\title{
A Comparison Between Different Doses of intrathecal nalbuphine with Bubivacaine and Intrathecal Fentanyl with Bubivacine during elective Caesarean Section under Spinal Anesthesia; A Prospective Randomized Double Blind Control Trial
}

M.A.El-Rabaey, E.M.Abd- Elazeem,D.H.Abd - Elhameed and A.M.Elsaid

Anaesthesia and intensive care unit, Dept., Faculty of Medicine, Benha Univ., Benha, Egypt E-mail:

\begin{abstract}
Background: Spinal anaesthesia (subarachnoid block) is the most popularly performed procedure in the field of anaesthesiology. The aim of the present study was to compare intrathecal $10 \mathrm{mg}$ of $0.5 \%$ hyperbaric bupivacaine versus intrathecal $10 \mathrm{mg}$ of $0.5 \%$ hyperbaric bubivaciane with 25 microgram fentanyl versus nalbuphine in doses 1 , 5 and $10 \mathrm{mg}$ with $10 \mathrm{mg}$ of $0.5 \%$ hyperbaric bupivacaine in patients undergoing elective caesarean section under subarachnoid block (SAB). Methods: This study included 100 patients were divided into 5 groups randomly allocated using a sealed envelope technique each group contain 20 patients; group A (control group): intrathecal10 $\mathrm{mg}$ of $0.5 \%$ hyperbaric bupivacaine, group B: intrathecal10mg of $0.5 \%$ hyperbaric bupivacaine + fentanyl 25 microgram. group is group C: intrathecal10 $\mathrm{mg}$ of $0.5 \%$ hyperbaric bupivacaine+ nalbuphine $1 \mathrm{mg}$. group D: intrathecal $10 \mathrm{mg}$ of $0.5 \%$ hyperbaric bupivacaine + nalbuphine $5 \mathrm{mg}$. group E: intrathecal $10 \mathrm{mg}$ of $0.5 \%$ hyperbaric bupivacaine + nalbuphine $10 \mathrm{mgResults} \&$ Conclusion: Nalbuphine $0.8 \mathrm{mg}$ is better than fentanyl in enhancing the period of postoperative complete and effective analgesia, diminishing the need of postoperative rescue analgesics and has better features such as anti-pruritic, lesser shivering, nausea and vomiting so nalbuphine $0.8 \mathrm{mg}$ is safe, valuable and the best among the groups.
\end{abstract}

Keywords: Intrathecal, Nalbuphine, Bubivacaine, Fentanyl, Caesarean Section.

\section{Introduction}

Spinal anaesthesia (subarachnoid block) is the most popularly performed procedure in the field of anaesthesiology. Hyperbaric bupivacaine, the local anaethetic most commonly used, has limitation as its effect lasts only for 1.5-2.0 hours. [1]

Hence a lot of adjuvants have been tried to enhance the analgesic effect of bupivacaine. Opioids have been found to prolong anaesthesia and analgesia, have been seen to improve the quality of analgesia and provide haemodynamic stability. The rationale for the combination of opioids and local anesthetics is that these two types of drugs eliminate pain by acting at two different sites. Local anesthetics act at the nerve axon and the opioid at the receptor site in the spinal cord [2]

Subarachnoid block is the preferred anaesthesia for cesarean section, being simple to perform with rapid onset. Regional anaesthesia for gynaecological procedures has emerged as an important technique with simplicity, rapid onset of action, good muscle relaxation. Adding adjuvant drugs to intrathecal local anesthetics improves quality and duration of sensory blockade and prolongs postoperative analgesia. Intrathecal opioids are synergistic with local anesthetics, thereby intensifying the sensory block without increasing sympathetic block. [3]

Postoperative pain is associated with lot of negative outcomes like cardiovascular events, poor ventilation, impaired wound healing and poor patient satisfaction [4].

Fentanyl is a lipophilic opioid with a rapid onset following intrathecal injection improves quality of anesthesia without producing significant side effects and improves post-operative analgesia and hemodynamic stability. [5]

Nalbuphine is a semi-synthetic opioid agonistantagonist analgesic of the phenanthrene series. The drug has been shown to have lesser propensity to cause respiratory depression when compared to morphine in several studies including those in pregnant population. [6]

Previous studies have shown that Intrathecal administration of Nalbuphine produced a significant analgesia accompanied by minimal pruritis and respiratory depression. Various doses of Nalbuphine were tried but still there is a controversy about the most effective dose. [7]

The study aims to compare intrathecal $10 \mathrm{mg}$ of $0.5 \%$ hyperbaric bupivacaine versus intrathecal 10 $\mathrm{mg}$ of $0.5 \%$ hyperbaric bubivaciane with 25 microgram fentanyl versus nalbuphine in doses 1,5 and $10 \mathrm{mg}$ with $10 \mathrm{mg}$ of $0.5 \%$ hyperbaric bupivacaine in patients undergoing elective caesarean section under subarachnoid block (SAB).

\section{Patients and methods}

This prospective randomized controlled study was conducted after obtaining institutional committee approval of the university and obtaining written informed consent.

This study had been conducted on women planned for radical mastectomy.

\subsection{Inclusion criteria}

- ASA grade I-II.

- Patients' age ranges between (20-35) years old.

- Undergoing elective caesarean section. 


\subsection{Exclusion criteria}

- Patients' refusal.

- Patients who have contraindications to spinal anaesthesia if any.

- Patients younger than 20 years old or older than 35 years old.

- Patients with pulmonary, renal, cardiac, hepatic problems .

- Infection at the site of the procedure.

- Patients allergic to the drug.

- Patient with coagulopathey.

- patients receiving phenothiazine, other tranquilizers, hypnotics or other central nervous system depressants (including alcohol).

- patients suffering from peripheral or central neurological disease.

- Patients with body weight more than $100 \mathrm{~kg}$ or less than $40 \mathrm{~kg}$ and height less than $145 \mathrm{~cm}$ or more than $160 \mathrm{~cm}$.

- Emergency caesarean section.

\subsection{Patients were randomized into 5 groups}

100 patients were divided into 5 groups they randomly allocated using a sealed envelope technique each group contain 20 patients:

- The 1st group is group A (control group): intrathecal10 $\mathrm{mg}$ of $0.5 \%$ hyperbaric bupivacaine

- The 2nd group is group B: intrathecal10mg of $0.5 \%$ hyperbaric bupivacaine + fentanyl 25 microgram.

- The 3rd group is group C: intrathecal10 mg of $0.5 \%$ hyperbaric bupivacaine+ nalbuphine $1 \mathrm{mg}$.

- The 4th group is group D: intrathecal10 mg of $0.5 \%$ hyperbaric bupivacaine + nalbuphine 5 $\mathrm{mg}$.

- The 5th group is group $\mathbf{E}$ : intrathecal10mg of $0.5 \%$ hyperbaric bupivacaine + nalbuphine 10 mg.

- All patients included in the study were subjected to the following:

- Detailed history taking

- Careful clinical examination

- Investigations: liver function tests (AST, ALT, ALP, serum bilirubin, serum albumin, Prothrombin time and I.N.R.), Serum creatinine.
Complete blood count (CBC). HBsAg, HCV Ab, HBA1C .for diabetic patients, Thyroid function tests, Lipid profile

- We assess pain for patients group as a baseline by (VAS) visual analogue scale which is a valid and reliable measure of chronic pain intensity, as well as acute pain measurement using a ruler.

An Official permission was obtained from in Benha University Hospitals. An official permission was obtained from anesthesiology Department. Approval from ethical committee in the faculty of medicine (Institutional Research Board IRB).Informed consent was obtained from all participants after being informed about the aims and process of the study as well as applicable objectives.

\subsection{Statistical Analysis}

Data entry, processing and statistical analysis was carried out using using SPSS version 20(Statistical Package for the Social Sciences). Tests of significance (Kruskal-Wallis, Wilcoxon's, Chi square, logistic regression analysis, and Spearman's correlation) were used. Data were presented and suitable analysis was done according to the type of data (parametric and non-parametric) obtained for each variable. P-values less than 0.05 (5\%) was considered to be statistically significant. P- value: level of significance, $\mathrm{P}>0.05$ : Non-significant (NS). $\mathrm{P}<0.05$ : Significant $(\mathrm{S}) . \mathrm{P}<0.01$ : Highly significant (HS). Descriptive statistics: Mean, Standard deviation $( \pm \mathrm{SD})$ and range for parametric numerical data, while Median and Inter-quartile range (IQR) for nonparametric numerical data. Frequency and percentage of non-numerical data. Analytical statistics: KruskalWallis test was used to assess the statistical significance of the difference of a non-parametric variable between more than two study groups. oneway ANOVA for continuous normally distributed variables. Post hoc analysis after ANOVA was performed using the Tukey test. ,with post hoc analysis by means of the Mann-Whitney $\mathrm{U}$ test.

\section{Results}

No significant differences were found between studied groups regarding age or anthropometric measurements. table (1)

Table (1) Comparison of age among studied groups.

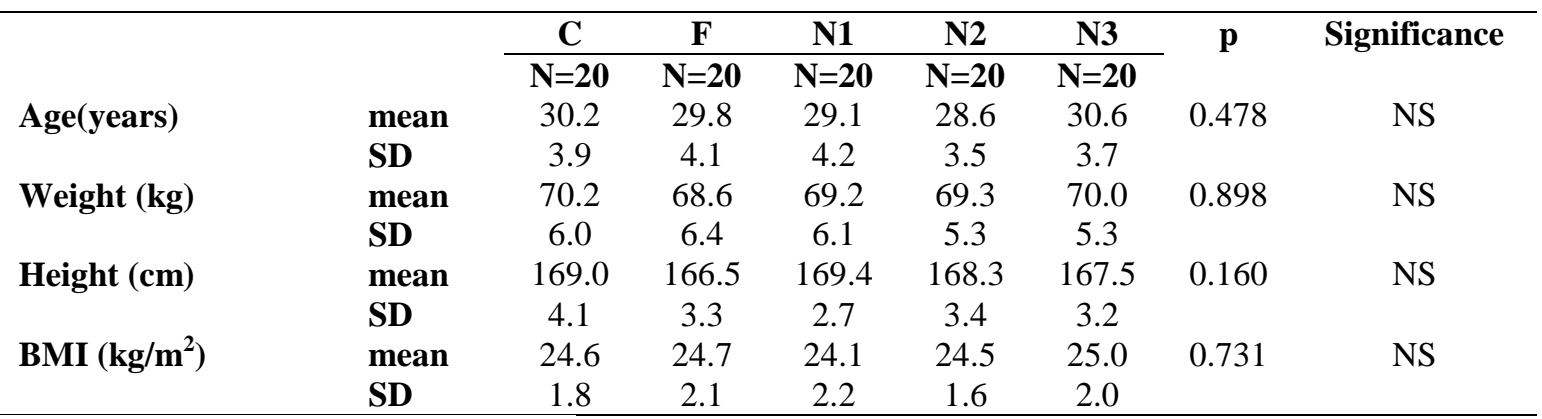

SD, Standard deviation; NS, non significant. 
Onset of sensory block was earliest in F group, when compared to other groups. Complete motor block differed significantly between studied groups, it was earlier in F and N3, followed by N2, N1, and lastly C groups respectively. No significant differences were found between studied groups regarding highest level of sensory blockade. Table (2)

Duration of sensory blockade differed significantly between studied groups, it was longest in N3, followed by F, then N2, N1, while the shortest duration was associated with $\mathrm{C}$ group. No significant differences were found between studied groups regarding duration of motor blockade. Table (3)
C group was associated with the highest frequency in nausea, vomiting and shivering, then $\mathrm{F}$ group, with no significant differences between all studied groups. Pruritus was significantly associated with F group compared to other studied group. Table (4)

The duration of effective analgesia differed signifcantly between studied groups, it was longest in $\mathrm{N} 3$, followed by F groups, then N2, N1 and lastly C groups. Fig. (1)

Total number of rescue analgesics required in 24 hours period differed significantly between studied groups, it was least in N3, followed by N2, N1 groups, then $\mathrm{F}$ and lastly $\mathrm{C}$ groups. Fig. (2).

Table (2) Comparison of sensory blockade data among studied groups.

\begin{tabular}{llccccccc}
\hline & & $\mathbf{C}$ & $\mathbf{F}$ & $\mathbf{N 1}$ & $\mathbf{N 2}$ & $\mathbf{N 3}$ & p & Significance \\
& & $\mathbf{N = 2 0}$ & $\mathbf{N = 2 0}$ & $\mathbf{N = 2 0}$ & $\mathbf{N = 2 0}$ & $\mathbf{N = 2 0}$ & & \\
\hline Onset of sensory blockade & mean & 1.7 & 1.5 & 1.7 & 1.6 & 1.6 & $<0.001$ & $\mathrm{~S}$ \\
& SD & 0.2 & 0.02 & 0.1 & 0.1 & 0.1 & & \\
& $*$ & $\mathrm{a}$ & $\mathrm{b}$ & $\mathrm{a}$ & $\mathrm{a}$ & $\mathrm{a}$ & & \\
Complete motor blockade & mean & 5.9 & 5.6 & 5.8 & 5.7 & 5.6 & 0.020 & $\mathrm{~S}$ \\
(min) & SD & 0.3 & 0.1 & 0.4 & 0.4 & 0.3 & & \\
Highest level of sensory & $*$ & $\mathrm{a}$ & $\mathrm{b}$ & $\mathrm{a}$ & $\mathrm{a}, \mathrm{b}$ & $\mathrm{b}$ & & \\
blockade (min) & mean & 6.4 & 6.3 & 6.4 & 6.3 & 6.3 & 0.802 & $\mathrm{NS}$ \\
\hline
\end{tabular}

SD, Standard deviation; NS, non significant; S, significant. *, Different letters indicate significance.

Table (3) Comparison of duration of blockade among studied groups.

\begin{tabular}{llccccccc}
\hline & & $\mathbf{C}$ & $\mathbf{F}$ & $\mathbf{N 1}$ & $\mathbf{N 2}$ & $\mathbf{N 3}$ & p & Significance \\
& & $\mathbf{N = 2 0}$ & $\mathbf{N = 2 0}$ & $\mathbf{N = 2 0}$ & $\mathbf{N = 2 0}$ & $\mathbf{N = 2 0}$ & & \\
\hline Duration of sensory & mean & 118.2 & 152.3 & 134.4 & 141.5 & 154.3 & $<0.001$ & \\
blockade ( min) & SD & 3.4 & 2.4 & 3.6 & 3.0 & 3.1 & & \\
& $*$ & $\mathrm{a}$ & $\mathrm{b}$ & $\mathrm{c}$ & $\mathrm{d}$ & $\mathrm{e}$ & & \\
Duration of motor blockade & mean & 138.8 & 141.9 & 139.4 & 140.6 & 141.0 & 0.221 & $\mathrm{NS}$ \\
(min) & SD & 2.9 & 7.9 & 4.0 & 3.0 & 2.9 & & \\
\hline
\end{tabular}

SD, Standard deviation; NS, non significant; S, significant. *, Different letters indicate significance.

Table (4) Comparison of side effects among studied groups.

\begin{tabular}{|c|c|c|c|c|c|c|c|c|}
\hline & & $\begin{array}{c}\mathrm{C} \\
\mathbf{N}=\mathbf{2 0}\end{array}$ & $\begin{array}{c}F \\
\mathbf{N}=\mathbf{2 0}\end{array}$ & $\begin{array}{c}\mathrm{N} 1 \\
\mathrm{~N}=20\end{array}$ & $\begin{array}{c}\mathrm{N} 2 \\
\mathrm{~N}=20\end{array}$ & $\begin{array}{c}\mathbf{N 3} \\
\mathbf{N}=\mathbf{2 0}\end{array}$ & $\mathbf{p}$ & Significance \\
\hline \multirow[t]{2}{*}{ Nausea and vomiting } & $\mathbf{N}$ & 5 & 4 & 1 & 1 & 1 & 0.173 & NS \\
\hline & $\%$ & $25 \%$ & $20 \%$ & $5 \%$ & $5 \%$ & $5 \%$ & & \\
\hline \multirow[t]{2}{*}{ shivering } & $\mathbf{N}$ & 3 & 2 & 1 & 1 & 1 & 0.853 & NS \\
\hline & $\%$ & $15 \%$ & $10 \%$ & $5 \%$ & $5 \%$ & $5 \%$ & & \\
\hline \multirow[t]{3}{*}{ Pruritus } & $\mathbf{N}$ & 0 & 4 & 0 & 0 & 0 & 0.006 & $\mathbf{S}$ \\
\hline & $\%$ & $0 \%$ & $20 \%$ & $0 \%$ & $0 \%$ & $0 \%$ & & \\
\hline & $*$ & $\mathrm{a}$ & $\mathrm{b}$ & $\mathrm{a}$ & $\mathrm{a}$ & $\mathrm{a}$ & & \\
\hline
\end{tabular}

$\mathrm{N}$, number; NS, non significant; S, significant. *, Different letters indicate significance. 


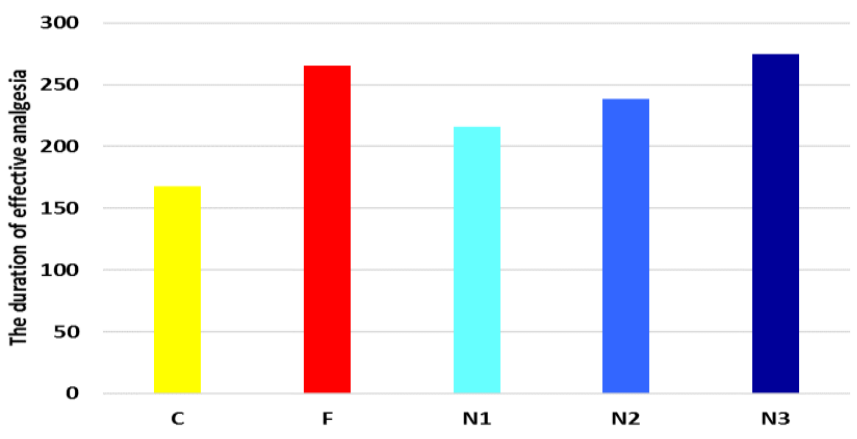

Fig. (1)Duration of effective analgesia among studied groups.

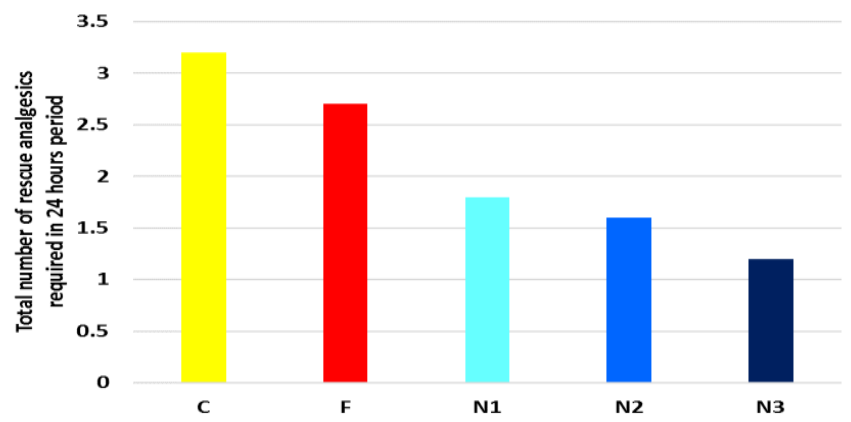

Fig (2) Total number of rescue analgesics required in 24 hours period among studied groups.

\section{Discussion}

The current study showed that onset of sensory block was earliest in $\mathrm{F}$ group, when compared to other groups. Complete motor block differed significantly between studied groups, it was earlier in $\mathrm{F}$ and N3, followed by $\mathrm{N} 2, \mathrm{~N} 1$, and lastly $\mathrm{C}$ groups respectively. No significant differences were found between studied groups regarding highest level of sensory blockade. Duration of sensory blockade differed significantly between studied groups, it was longest in N3, followed by F, then N2, N1, while the shortest duration was associated with $\mathrm{C}$ group. No significant differences were found between studied groups regarding duration of motor blockade.

Our results were supported by study of Makram et al., [8] as they reported that There was a statistical significance as fentanyl group (group $\mathrm{F}$ and group N3) was superior to groups (groups $\mathrm{N} 1$ andN2) and control group (group $\mathrm{C}$ ) in spreading onset of sensory block with $\mathrm{P}$ - value $=0.015$. Group $\mathrm{F}$ show rapid onset sensory blockade than group N3, but this difference was insignificant. On comparison between the five groups regarding highest level of sensory blockade and onset of complete motor blockade it was found both group $\mathrm{F}$ and N3 was fast but this increasing was insignificant $(\mathrm{p}>0.05)$. The 2 -segment regression of sensory blockade and period of motor blockade were more prolonged with adding nalbuphine $(0.8 \mathrm{mg})$ (group $\mathrm{N} 3$ ) to intrathecal bupivacaine than addition of fentanyl $(25 \mu \mathrm{g}$ ) (group F) than the other groups though statistically insignificant, while in the group $\mathrm{C}$ there was a statistically significant decrease than the other groups $(\mathrm{p}<0.05)$.

In the study of Ahmed et al., [9] the onset of sensory and motor block was found to be similar in all the four groups. There was no statistically significant difference among groups $(\mathrm{P}>0.05)$. The onset of sensory block were $7.5 \pm 1.2 \mathrm{~min}, 7.2 \pm 1.5$ $\mathrm{min}, 7.4 \pm 1.3 \mathrm{~min}$, and $7.1 \pm 1.1 \mathrm{~min}$ in groups $\mathrm{A}, \mathrm{B}$, $\mathrm{C}$, and $\mathrm{D}$, respectively. The times of the onset of motor block were $8.5 \pm 1.0 \mathrm{~min}, 8.4 \pm 1.4 \mathrm{~min}, 8.5 \pm$ $1.1 \mathrm{~min}$, and $8.2 \pm 1.1 \mathrm{~min}$ in groups $\mathrm{A}, \mathrm{B}, \mathrm{C}$, and $\mathrm{D}$, respectively. There was no statistically significant difference found in duration of motor block among groups $(\mathrm{P}>0.05)$. The duration of motor block was $116.6 \pm 11.0 \mathrm{~min}, 123.8 \pm 16.8 \mathrm{~min}, 123.2 \pm 13.6$ min, and $125.6 \pm 10.5 \mathrm{~min}$ in groups $\mathrm{A}, \mathrm{B}, \mathrm{C}$, and $\mathrm{D}$, respectively. The statistically significant difference in duration of two-segment regression was seen when group A was compared with other three groups (B, C, and D) The mean durations of two-segment regression was $82.4 \pm 23.1 \mathrm{~min}, 98.7 \pm 21.4 \mathrm{~min}$, $132.7 \pm 21.1 \mathrm{~min}$, and $117.2 \pm 23.9 \mathrm{~min}$ in group $\mathrm{A}$, $\mathrm{B}, \mathrm{C}$, and $\mathrm{D}$, respectively.

In the previous study, in inter-group comparison, they observed a significant result on comparison of groups $\mathrm{A}$ and $\mathrm{C}$, groups $\mathrm{A}$ and $\mathrm{D}$, and groups $\mathrm{B}$ and D. In groups $A$ and $B$ and in groups $C$ and $D$, the result was found insignificant. In group A: The patients received a dose of $15 \mathrm{mg}$ of $0.5 \%$ hyperbaric bupivacaine, in group B: The patients received a dose of $15 \mathrm{mg}$ of $0.5 \%$ hyperbaric bupivacaine plus $0.8 \mathrm{mg}$ of nalbuphine, in group $\mathrm{C}$ : The patients received a dose of $15 \mathrm{mg}$ of $0.5 \%$ hyperbaric bupivacaine plus 
$1.6 \mathrm{mg}$ of nalbuphine, and in group D: The patients received a dose of $15 \mathrm{mg}$ of $0.5 \%$ hyperbaric bupivacaine plus $2.4 \mathrm{mg}$ of nalbuphine intrathecally. In all groups, normal saline was added to make total volume of $3.5 \mathrm{~mL}$ [9].

Venkata et al., [10] observed significantly faster onset of sensory block with fentanyl as adjuvant. However, in the study of Bindra et al., [11], the difference in the time of onset of sensory and motor block was statistically nonsignificant (NS) among the groups $(\mathrm{P}>0.05)$. The mean duration of sensory block was $108.46 \pm 5.51 \mathrm{~min}$ in Group I, $111.46 \pm$ $6.49 \mathrm{~min}$ in Group II, and 86.06 $\pm 8.72 \mathrm{~min}$ in Group III. The mean duration of sensory block was significantly higher $(\mathrm{P}<0.001)$ in patients receiving nalbuphine and fentanyl as compared to Group III. The mean duration of motor block (time required for motor block to return to Bromage's Grade 1 from the time of onset of motor block) was $154.72 \pm 5.89 \mathrm{~min}$ in Group I, $154.44 \pm 5.24 \mathrm{~min}$ in Group II, and $124.94 \pm 9.28 \mathrm{~min}$ in Group III. The mean duration of motor block was significantly higher $(\mathrm{P}<0.001)$ in Group I and II patients than in Group III.

Gomaa et al., [12] compared intrathecal nalbuphine $0.8 \mathrm{mg}$ and fentanyl $25 \mu \mathrm{g}$ and found that there was no statistically significant difference in onset of sensory block between fentanyl (1.64 min) and nalbuphine $(1.60 \mathrm{~min})$ group. They found significantly rapid onset of motor block in patients given fentanyl $(5.57 \mathrm{~min})$ than in patients given nalbuphine (5.72 $\mathrm{min}$ ) in cesarean section.

In the study of Ahluwalia et al., [13], the onset time of sensory block in Group B was $3.78 \pm 1.31$ $\min$ while in Group $\mathrm{N}$ was $1.29 \pm 0.43 \min (\mathrm{P}<$ $0.05)$, but statistically insignificant result was observed in between groups in onset of motor blockade. The duration of sensory block in Group B and Group $\mathrm{N}$ was $123.65 \pm 21.23 \mathrm{~min}$ and $166.24 \pm$ $29.84 \mathrm{~min}(\mathrm{P}<0.05)$ while similar statistical significance was observed in between groups for duration of motor blockade (Group B; $178.67 \pm 28.34$ min and Group N; $256.41 \pm 33.41 \mathrm{~min})$. Duration of analgesia in Group B (201.31 $\pm 34.31 \mathrm{~min})$ and Group N (298.43 $\pm 30.92 \mathrm{~min})$ was statistically significant among groups $(\mathrm{P}<0.05)$.

In a study conducted by Jyothi et al., [14], the mean time of onset of sensory blockade between the groups is comparable with the $\mathrm{P}$ value $>0.05$ which is statistically not significant. Two segment regression of sensory blockade is significantly prolonged by addition of intrathecal nalbuphine as seen with Groups B, C, and D when compared with group A with bupivacaine alone. The duration of analgesia was significantly prolonged with the addition of nalbuphine as compared with bupivacaine alone. Patients were randomly allocated to four groups receiving either intrathecal $15 \mathrm{mg}$ of bupivacaine + $0.5 \mathrm{~mL}$ normal saline alone or $15 \mathrm{mg}$ of bupivacaine with either of nalbuphine $0.8,1.6$, and $2.5 \mathrm{mg}+0.5$ $\mathrm{mL}$ normal saline.
In the study in our hands, no significant differences were found between studied groups regarding Respiratory rate, oxygen saturation, SBP, DBP\& HR among studied groups at different time points. No significant differences were found between studied groups regarding postoperative Respiratory rate, oxygen saturation, SBP, DBP\& HR among studied groups at different time points.

Our results were in agreement with study of Bindra et al., [11] as they reported that the three groups were comparable with regard to BP (mean, systolic, and diastolic), heart rate, respiratory rate, and $\mathrm{SpO} 2$. Intrathecal opioids are synergistic with local anesthetics and intensify the sensory block without increasing the sympathetic block.

Our results are in accordance with Gomaa et al, [12] who observed no significant difference in hemodynamic variables in the study groups.

Also, Ahluwalia et al., [13], revealed that the results were comparable with respect to the intraoperative mean $\mathrm{HR}$, systolic/DBP, SpO2, respiratory rate between the groups.

The present study showed that as regard side effects; C group was associated with the highest frequency in nausea, vomiting and shivering, then $\mathrm{F}$ group, with no significant differences between all studied groups. While pruritus was significantly associated with $\mathrm{F}$ group compared to another studied group.

Our results were supported by study of Makram et al., [8] as they reported that the rates of pruritis were fundamentally higher in fentanyl bunch than in nalbuphine bunches which were nil that is clarified by the counter pruritic impact of $\mu$ receptor enemies and control bunch likewise the examination was factually critical in the rate of retching and queasiness and shuddering which were higher in benchmark group and fentanyl bunch than nalbuphine gatherings.

The higher frequencies of pruritis and shuddering in fentanyl bunch that were recognized in present examination not distinguished inside the investigation by Vashishth et al., [15] who looked at the outcomes of adding nalbuphine or fentanyl as a partner with bupivacaine for spinal sedation in patients booked for lower stomach and lower appendage medical procedures, and that they saw fentanyl is in a way that is better than nalbuphine regarding beginning of square and length of absence of pain with no impressive hemodynamic unsettling influences and unfriendly effects' and this could be clarified by the diverse fentanyl dosages that have been utilized in each investigation and distinctive patient gathering.

However, in the study of Jyothi et al., [14], there were no serious complications like nausea, vomiting, urinary retention, shivering, pruritis, hypotension, or respiratory depression. This difference may be attributed to different inclusion criteria between their study and ours. 


\section{Conclusion}

Nalbuphine $0.8 \mathrm{mg}$ is better than fentanyl in enhancing the period of postoperative complete and effective analgesia, diminishing the need of postoperative rescue analgesics and has better features such as anti-pruritic, lesser shivering, nausea and vomiting so nalbuphine $0.8 \mathrm{mg}$ is safe, valuable and the best among the groups.

\section{References}

[1] S. Naaz, U. Shukla, S. Srivastava, E. Ozair, and A. Asghar, "A comparative study of analgesic effect of intrathecal nalbuphine and fentanyl as adjuvant in lower limb orthopaedic surgery," J. Clin. diagnostic Res. JCDR, vol. 11, no. 7, p. UC25, 2017.

[2] J. A. Alhashemi and A. M. Kaki, "Effect of intrathecal tramadol administration on postoperative pain after transurethral resection of prostate," Br. J. Anaesth., vol. 91, no. 4, pp. 536-540, 2003.

[3] C. G. Pick, D. Paul, and G. W. Pasternak, "Nalbuphine, a mixed kappa 1 and kappa 3 analgesic in mice.," J. Pharmacol. Exp. Ther., vol. 262, no. 3, pp. 1044-1050, 1992.

[4] A. Gupta, K. Kaur, S. Sharma, S. Goyal, S. Arora, and R. S. R. Murthy, "Clinical aspects of acute post-operative pain management \& its assessment," J. Adv. Pharm. Technol. Res., vol. 1, no. 2, p. 97, 2010.

[5] H. Chavda, P. J. Mehta, and A. H. Vyas, "A comparative study of intrathecal fentanyl and sufentanil with bupivacaine heavy for postoperative analgesia," Int J Anesth., vol. 20, no. 1, pp. 2-8, 2009.

[6] Z. Zeng et al., "A comparision of nalbuphine with morphine for analgesic effects and safety: meta-analysis of randomized controlled trials," Sci. Rep., vol. 5, no. 1, pp. 1-8, 2015.

[7] A. K. Tiwari, G. S. Tomar, and J. Agrawal, "Intrathecal bupivacaine in comparison with a combination of nalbuphine and bupivacaine for subarachnoid block: A randomized prospective double-blind clinical study," Am. J. Ther., vol. 20, no. 6, pp. 592-595, 2013.

[8] E. F. Makram, I. S. Abd-Elazeem, M. A. Khashba, and L. E. Youssef, "A Comparative Study between Hyperbaric Bupivacaine Alone Versus Fentanyl Versus Nalbuphine in Three Different Doses Intrathecally Adjuvant to Hyperbaric Bupivacaine for Lower Abdominal Surgeries," Benha J. Appl. Sci., vol. 5, no. 8 part (1), pp. 1-8, 2020.

[9] F. Ahmed, H. Narula, M. Khandelwal, and D. Dutta, "A comparative study of three different doses of nalbuphine as an adjuvant to intrathecal bupivacaine for postoperative analgesia in abdominal hysterectomy," Indian J. Pain, vol. 30, no. 1, p. 23, 2016.
[10] H. G. Venkata, S. Pasupuleti, U. G. Pabba, S. Porika, and G. Talari, "A randomized controlled prospective study comparing a low dose bupivacaine and fentanyl mixture to a conventional dose of hyperbaric bupivacaine for cesarean section," Saudi J. Anaesth., vol. 9, no. 2, p. 122, 2015.

[11] T. K. Bindra, P. Kumar, and G. Jindal, "Postoperative analgesia with intrathecal nalbuphine versus intrathecal fentanyl in cesarean section: A double-blind randomized comparative study," Anesth. essays Res., vol. 12, no. 2, p. 561, 2018.

[12] H. M. Gomaa, N. N. Mohamed, H. A. H. Zoheir, and M. S. Ali, "A comparison between post-operative analgesia after intrathecal nalbuphine with bupivacaine and intrathecal fentanyl with bupivacaine after cesarean section,” Egypt. J. Anaesth., vol. 30, no. 4, pp. 405-410, 2014.

[13] P. Ahluwalia, A. Ahluwalia, R. Varshney, S. Thakur, and S. Bhandari, "A prospective randomized double blind study to evaluate the effects of intrathecal nalbuphine in patients of lower abdominal surgeries under spinal anaesthesia," Int J Sci Stud, vol. 3, no. 3, pp. 19-23, 2015.

[14]B. Jyothi, S. Gowda, and S. I. Shaikh, "A comparison of analgesic effect of different doses of intrathecal nalbuphine hydrochloride with bupivacaine and bupivacaine alone for lower abdominal and orthopedic surgeries," Indian J. Pain, vol. 28, no. 1, p. 18, 2014.

[15] T. Vashishth, G. Sharma, S. Garg, S. Vashishth, S. Pathak, and V. A. Tyagi, "Comparative study of Nalbuphine and Fentanyl with Bupivacaine in spinal anaesthesia for lower abdominal and lower limb surgeries," Nat J Med Dent Res, vol. 4, pp. 93-100, 2016. 